\title{
Involvement of phosphoinositide 3-kinase in insulin stimulation of MAP-kinase and phosphorylation of protein kinase-B in human skeletal muscle: implications for glucose metabolism
}

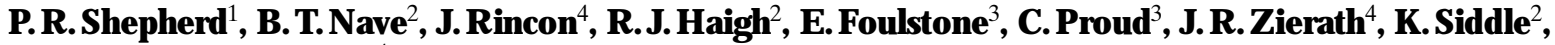 \\ H. Wallberg-H enriksson ${ }^{4}$ \\ ${ }^{1}$ Department of Biochemistry, University College London, UK \\ ${ }^{2}$ Department of Clinical Biochemistry, University of Cambridge, UK \\ ${ }^{3}$ Department of Biosciences, University of Kent, Canterbury, UK \\ ${ }^{4}$ Department of Clinical Physiology, Karolinska Hospital, Stockholm, Sweden
}

Summary Isolated skeletal muscle from healthy individuals was used to evaluate the role of phosphoinositide 3-kinase (PI 3-kinase) in insulin signalling pathways regulating mitogen activated protein kinase (MAP-kinase) and protein kinase-B and to investigate whether MAP-kinase was involved in signalling pathways regulating glucose metabolism. Insulin stimulated glycogen synthase activity ( $\approx 1.7$ fold $)$, increased 3-o-methylglucose transport into human skeletal muscle strips ( $\approx 2$ fold) and stimulated phosphorylation of the p42 ERK-2 isoform of MAP-kinase. This phosphorylation of p42 ERK2 was not blocked by the PI 3-kinase inhibitors LY294002 and wortmannin although it was blocked by the MAPkinase kinase (MEK) inhibitor PD 98059. However, PD98059 (up to $20 \mu \mathrm{mol} / \mathrm{l}$ ) did not block insulin activation of glycogen synthase or stimulation of 3-o-methylglucose transport. Wortmannin and LY294002 did block insulin stimulation of protein kinase-B (PKB) phosphorylation and stimulation of 3-o-methylglucose transport was inhibited by wortmannin $\left(\mathrm{IC}_{50} \approx 100 \mathrm{nmol} / \mathrm{l}\right)$. These results indicate that MAP-kinase is activated by insulin in human skeletal muscle by a PI 3-kinase independent pathway. Furthermore this activation is not necessary for insulin stimulation of glucose transport or activation of glycogen synthase in this tissue. [Diabetologia (1997) 40: 1172-1177]

Keywords Muscle, human, insulin, phosphoinositide 3-kinase, Map-kinase, protein kinase B, glycogen synthase, glucose transport.
Insulin binding to its cell surface receptor activates a range of intracellular signalling cascades that ultimately result in the regulation of a number of important metabolic events within the cell [1]. Of particular importance is insulin stimulation of glucose transport and stimulation of glycogen deposition in muscle as this accounts for the bulk of insulin stimulated glucose disposal from the blood [2,3]. Peripheral insulin resistance at the level of skeletal muscle plays an important role in the development of hyperinsulinaemia

Corresponding author: Dr. P. Shepherd, Department of Biochemistry, University College London, Gower Street, London WC1E 6BT, UK

A bbreviations: MAP-kinase, Mitogen activated protein kinase; ERK, extracellular regulated protein kinase; PI 3-kinase, phosphoinositide 3-kinase; PKB, protein kinase-B (also known as akt); SDS-Page, sodiumdodecylsulphate polyacrylamide gel electrophoresis. and hyperglycaemia associated with obesity [4] and non-insulin-dependent diabetes [5]. The consensus of opinion is that defects in insulin signalling lead to the reduced ability of insulin to stimulate glucose disposal into muscle in insulin resistant individuals $[6,7]$.

Understanding the molecular mechanisms by which insulin regulates glucose transport and glycogen storage in skeletal muscle is therefore of great importance. Insulin acutely stimulates phosphoinositide-3 (PI 3)-kinase and evidence suggests that PI 3kinase activity is necessary [8-10] and sufficient [11, 12] for insulin stimulation of glucose transport and also necessary for insulin activation of glycogen synthase $[13,14]$. Further, there is evidence to suggest that protein kinase $\mathrm{B}(\mathrm{PKB})$ is an element of the signalling cascade leading from PI 3-kinase to activation of glycogen synthase in cell culture models $[15,16]$. Insulin's regulation of these pathways has not been investigated in intact human skeletal muscle. 
Indeed studies in rabbit muscle have suggested that glycogen synthase in muscle may be activated by insulin by a separate mitogen activated protein (MAP)-kinase dependent pathway [17]. However, a number of subsequent studies have concluded that MAP-kinase is not required for insulin stimulated activation of glycogen synthase in a range of cell culture systems (for review see [18]). These studies have not investigated the role of MAP-kinase in skeletal muscle but have assumed that the mechanism by which insulin stimulates glycogen synthase is conserved in all cell types. Given that the original scheme for insulin regulating glycogen synthase via a MAP-kinase dependent pathway was based on evidence obtained in skeletal muscle we have investigated the role of MAP-kinase in insulin signalling pathways regulating glucose metabolism in human skeletal muscle. We have also investigated the role of PI 3-kinase in pathways leading to the activation of MAP-kinase and PKB.

\section{Materials and methods}

M aterials. UDP-glucose, wortmannin, glucose 6-phosphate, bovine serum albumin (BSA) were from Sigma Chemicals, Poole, UK; ${ }^{125} \mathrm{I}$ - Protein A, ${ }^{3} \mathrm{H}-3$-o-methyl glucose and ${ }^{14} \mathrm{C}$ UDP-glucose were from Amersham, UK; LY294002 was supplied by Dr. B. Holloway, Zeneca Pharmaceuticals, Macclesfield, UK; PD98059, PD 98059 was supplied by Dr. A. Saltiel, Parke-Davis Pharmaceuticals Ann Arber, USA. Phospho-specific MAP-kinase antiserum was from New England Biolabs Beverly, Massachusetts, USA; a polyclonal antibody recognising both PKB- $\alpha$ and PKB- $\beta$ was supplied by Dr. B. Hemmings, Friedrich-Miescher Institute Basel, Switzerland; a polyclonal antibody recognising the $44 \mathrm{kDa}$ and $42 \mathrm{kDa}$ isoforms of MAP-kinase was supplied by Dr. J. Tavare, University of Bristol, UK.

Subjects. Muscle specimens were obtained from the vastus lateralis portion of the quadriceps femoris muscle from 19 healthy male subjects (age $28.4 \pm 0.7$ years, weight $76.6 \pm 2.1 \mathrm{~kg}$, height $181.3 \pm 1.9 \mathrm{~cm}$ and body mass index $23.4 \pm 0.4 \mathrm{~kg} / \mathrm{m}^{2}$, fasting glucose $4.9 \pm 0.2 \mathrm{mmol} / \mathrm{l}$ and serum insulin $41.4 \pm 2.4 \mathrm{pmol}$ ). None of the subjects were taking any medication. The nature, purpose and possible risks of the study were reviewed and approved by the ethical committee of the Karolinska Institute and were carefully explained to each individual before they gave their consent to participate. Following an overnight fast the subjects reported to the laboratory at 08.30 hours. A local anaesthetic (prilocain hydrochloride $10 \mathrm{mg} / \mathrm{ml}$ ) was administered subcutaneously $15 \mathrm{~cm}$ above the proximal border of the patella and a $4 \mathrm{~cm}$ incision was made. Two muscle specimens ( $250 \mathrm{mg}$ each) were excised for in vitro incubation and smaller muscle strips were prepared as described by Zierath [19].

Stimulation of muscle and determination of 3-0-methylglucose transport. After preparation, the smaller muscle strips (approximately $20 \mathrm{mg}$ ) were incubated at $35^{\circ} \mathrm{C}$ for $10 \mathrm{~min}$ in a recovery solution containing oxygenated Krebs-Henseleit buffer supplemented with $10 \mathrm{mmol} / \mathrm{l}$ (HEPES), $38 \mathrm{mmol} / \mathrm{l} \mathrm{mannitol,} 2 \mathrm{mmol} /$ 1 pyruvate and $0.1 \%$ BSA. The strips were subsequently incubated with inhibitors and insulin as indicated in the figure legends. For measurements of 3-o-methylglucose transport the buffer contained $5 \mathrm{mmol} / \mathrm{l}$ 3-o- $\left({ }^{3} \mathrm{H}\right)$ methylglucose and $35 \mathrm{mmol} / \mathrm{l}\left({ }^{14} \mathrm{C}\right)$ mannitol. The incubations were terminated by snap freezing the strip in liquid nitrogen and rapidly homogenising in ice cold homogenisation buffer containing $100 \mathrm{mmol} / \mathrm{l}$ $\mathrm{NaF}$ and $10 \mathrm{mmol} / \mathrm{l}$ EDTA. Cell debris were removed by centrifugation at $5000 \times \mathrm{g}$ for $1 \mathrm{~min}$. 3-0-methylglucose transport was calculated as previously described [20].

A ssessment of glycogen synthase activity. Glycogen synthase activity ratio was determined in precleared muscle homogenates essentially as previously described [21] using $6 \mathrm{mmol} / \mathrm{l}$ Uridine-diphospho-glucose in the presence and absence of $7.5 \mathrm{mmol} / \mathrm{l}$ glucose 6-phosphate.

A ssessment of Map-kinase activation. MAP-kinase activation was assessed using a gel mobility shift assay in which samples were run on SDS-PAGE and immunoblotted with the MAPkinase polyclonal antiserum or the phospho-specific MAP-kinase antiserum followed by ${ }^{125} \mathrm{I}$-protein A. Bands were quantitated on a Bas 2000 phosphoimager. For band shift experiments the results are expressed as percentage of the total doublet signal present in the upper band (phosphorylated active form).

Statistical analysis. Statistical differences between treatments were analysed using the Student's paired t-test.

\section{Results}

Insulin stimulation of M A P-kinase. The MAP-kinase antiserum used in the current study recognised both the phosphorylated and unphosphorylated forms of p42/p44 (ERK-2/ERK-1) MAP-kinase in 3T3-L1 adipocytes although the p44 isoform was undetectable in the human muscle preparations (Fig. $1 \mathrm{a}$ ). The antiserum detected a doublet in unstimulated muscle corresponding to phosphorylated (upper band) and unphosphorylated (lower band) forms of p42-ERK2 (Fig. 1 a). Using this method of assessing MAP-kinase phosphorylation it was found that approximately half of the p42 ERK2 existed in the phosphorylated form in unstimulated muscle strips. In vitro stimulation of human skeletal muscle strips with insulin caused an increase in the level of phosphorylation of p42 ERK2 as shown by decreased mobility on SDS-PAGE (Fig. 1a). This was confirmed using an antibody which only recognises the phosphorylated forms of p42/p44 (ERK-2/ERK-1) MAP-kinase. This antibody recognised a single band in human muscle lysates (Fig. 1 b) which corresponded to the upper band of the p42 ERK2 doublet recognised by the MAP-kinase antiserum. No band corresponding to p44 ERK1 was recognised by the phospho-specific MAP-kinase antiserum although such a band was clearly observed in 3T3-L1 adipocytes (data not shown). This antiserum also confirmed that there was significant phosphorylation of p42 ERK2 in unstimulated muscle and using the combined data obtained from blotting four separate muscle strips we find the amount of 
A

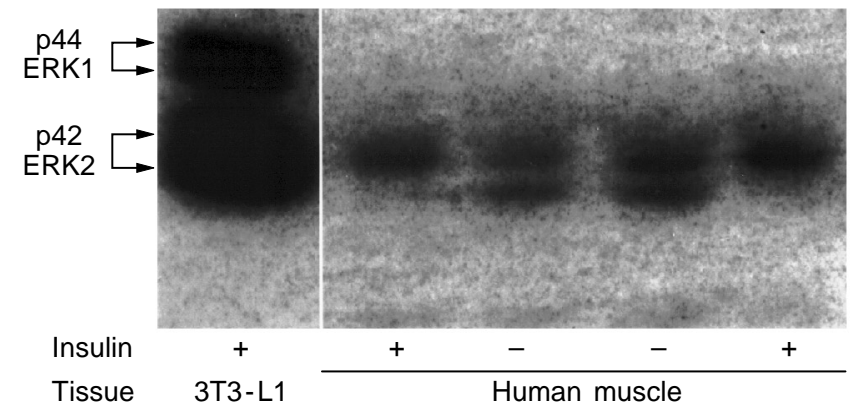

B

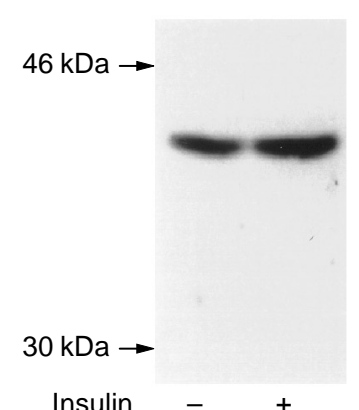

C

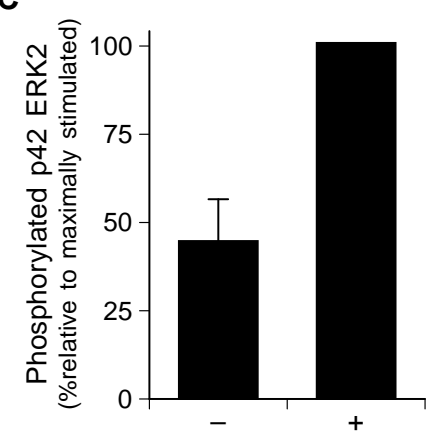

Fig. 1. A -C Insulin stimulates phosphorylation of p42 ERK-2 in human skeletal muscle. Muscle strips (or 3T3-L1 adipocytes) were preincubated with the indicated concentration of inhibitor or with vehicle for $10 \mathrm{~min}$ prior to stimulation with $1000 \mu \mathrm{U} / \mathrm{ml}$ insulin for $30 \mathrm{~min}$. Muscle was then snap frozen in liquid nitrogen and homogenised as described in methods. Muscle homogenates (100 $\mu \mathrm{g}$ protein/lane) were run on SDSPAGE, transferred to nitrocellulose and blotted with (A) a polyclonal antiserum which recognise both phosphorylated and unphosphorylated forms of p42 ERK-2 and p44 ERK-1; (B) a polyclonal antiserum which recognise only the phosphorylated forms of p42 ERK-2 and p44 ERK-1; (C) shows the quantitation of the p42 ERK-2 band identified by the phospho-specific MAP-kinase antibody in 4 unstimulated muscle strips and 4 insulin stimulated muscle strips. Results are expressed as mean relative to maximal stimulation \pm SEM

phosphorylated p42 ERK2 approximately doubled with insulin stimulation (Fig.1c). This is consistant with the results from the bandshift experiments which show that the proportion of p42 ERK-2 in the phosphorylated state was $58.7 \pm 2.9 \% \quad(n=25$, mean \pm SEM) in unstimulated muscle strips and this rose to $76.9 \pm 1.5 \%(n=21)(p<0.001)$ after 30 min stimulation with insulin indicating activation of $\mathrm{p} 42$ ERK-2 (Fig.1b). The enzyme activity associated with immunoprecipitates using this MAP-kinase antibody from unstimulated and insulin stimulated muscle closely paralleled the results seen in phospho specific MAP-kinase blots and the bandshift assays (data not shown).

The insulin induced increase in the amount of phosphorylated p42 ERK-2 was not affected by the PI 3-kinase inhibitor LY294002 at a concentration of $30 \mu \mathrm{mol} / \mathrm{l}$. Further, insulin caused a similar increase in p42 ERK-2 phosphorylation in the

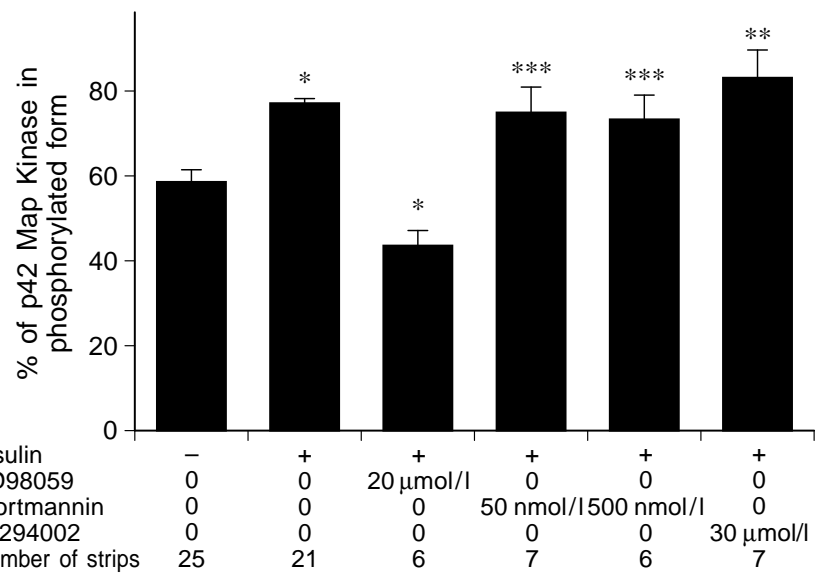

Fig. 2. Insulin stimulated phosphorylation of p42 ERK-2 is blocked by PD98059 but not by inhibitors of PI 3-kinase in human skeletal muscle. Muscle strips were preincubated with indicated concentration of inhibitor or with vehicle for $10 \mathrm{~min}$ prior to stimulation with $1000 \mu \mathrm{U} / \mathrm{ml}$ insulin for $30 \mathrm{~min}$. Muscle was then snap frozen in liquid nitrogen and homogenised as described in methods. Muscle homogenates (100 $\mathrm{gg}$ protein/lane) were run on SDS-PAGE, transferred to nitrocellulose and blotted with the polyclonal antiserum which recognise both phosphorylated and unphosphorylated forms of p42 ERK-2 and p44 ERK-1 the percentage of total p42 ERK-2 in the phosphorylated form was calculated (mean \pm SEM). The number of strips in each experiment as indicated and significance relative to unstimulated strips was $* p<0.01$, $* * p<0.05$ and $* * * p<0.10$

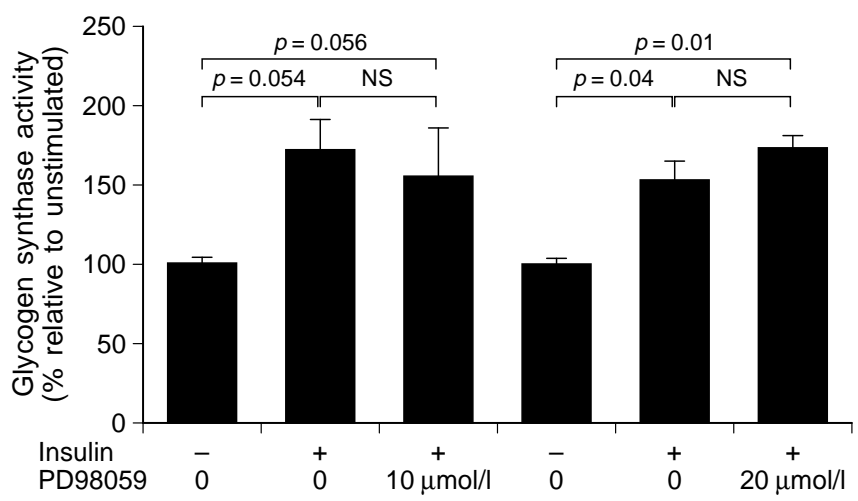

Fig. 3. Effect of PD 98059 on activation of glycogen synthase in human skeletal muscle. Muscle strips were preincubated with the indicated concentration of PD98059 or with vehicle for $10 \mathrm{~min}$ prior to stimulation with $2000 \mu \mathrm{U} / \mathrm{ml}$ insulin for a further $30 \mathrm{~min}$. Muscle was then snap frozen in liquid nitrogen and assayed for glycogen synthase activity as described in methods. Results shown are of a representative experiment performed in triplicate (mean \pm SEM). Similar results were obtained in three (in case of $10 \mu \mathrm{mol} / 1$ PD98059) and one (in case of $20 \mu \mathrm{mol} / \mathrm{l}$ PD98059) independent experiment

presence of 50 and $500 \mathrm{nmol} / \mathrm{l}$ wortmannin. These increases were consistantly found and while the increases over basal did not reach statistical significance ( $p=0.09$ and 0.08 , respectively), neither were they significantly different from the insulin stimulated levels of phosphorylation $(p=0.30$ and 0.21 , 


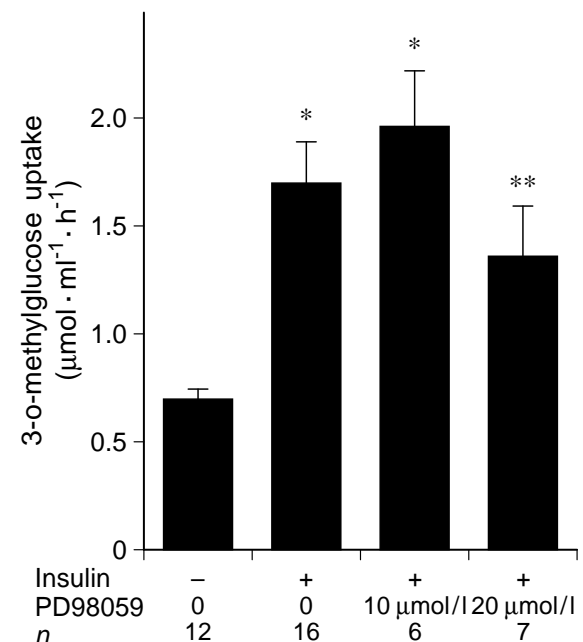

Fig. 4. Effect of PD98059 on activation of 3-o-methylglucose transport in human skeletal muscle. Muscle strips were preincubated with indicated concentration of PD98059 or with vehicle for $10 \mathrm{~min}$ prior to stimulation with $2000 \mu \mathrm{U} / \mathrm{ml}$ insulin for a further $30 \mathrm{~min}$. 3-o-methylglucose transport was assessed over the last $10 \mathrm{~min}$ of this insulin stimulation. Muscle was then snap frozen in liquid nitrogen and assayed for 3-o-methylglucose transport as described in methods. The results represent the mean of the indicated number of strips \pm SEM. Significance relative to unstimulated strips was $* p<0.01$, ** $p<0.05$

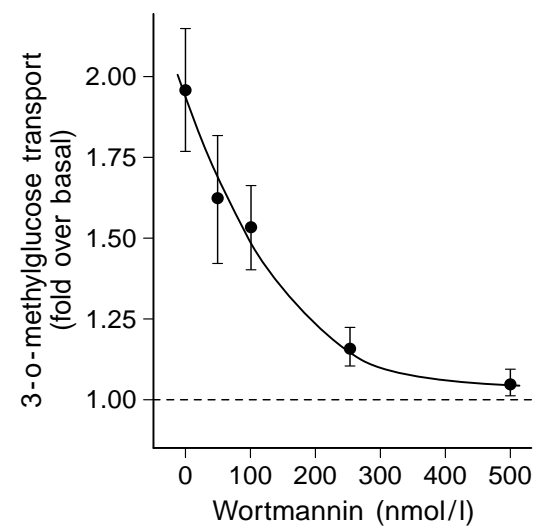

Fig. 5. Wortmannin blocks insulin stimulation of 3-o-methylglucose transport into human skeletal muscle. Muscle strips were preincubated with the indicated concentration of wortmannin for 10 min prior to addition of insulin at a concentration of $1000 \mu \mathrm{U} / \mathrm{ml}$. Muscle strips were incubated a total of a further $30 \mathrm{~min}$ with 3-o-methylglucose transport being measured over the final $15 \mathrm{~min}$ as indicated in the methods. Results for each point represent the mean of triplicate determinations \pm SEM

respectively) (Fig.2). Insulin stimulated PI 3-kinase activity is completely blocked by wortmannin at $50 \mathrm{nmol} / \mathrm{l}$ and LY294002 at concentrations above $10 \mu \mathrm{mol} / 1$ [9, 10]. Therefore, these findings indicate that PI 3-kinase activity is not required for insulin's stimulation of the MAP-kinase cascade in human skeletal muscle. However, preincubation with $10 \mu \mathrm{mol} / \mathrm{l}$ of the MEK inhibitor PD 98059 blocked

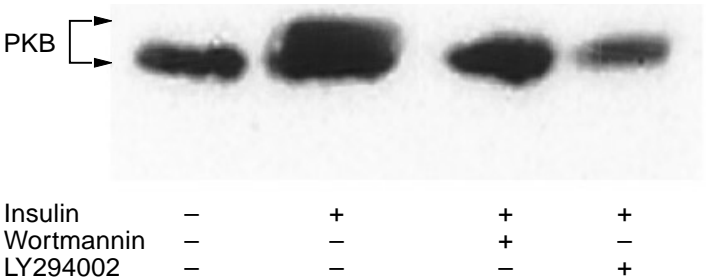

Fig. 6. Effect of Wortmannin and LY294002 on insulin stimulation of PKB in human skeletal muscle. Muscle strips were preincubated with the LY294002 $(8 \mu \mathrm{mol} / \mathrm{l})$ or wortmannin $(250 \mathrm{nmol} / \mathrm{l})$ for $10 \mathrm{~min}$ prior to addition of $1000 \mu \mathrm{U} / \mathrm{ml}$ insulin for $30 \mathrm{~min}$. Muscle was then snap frozen in liquid nitrogen and homogenised as described in methods. Muscle homogenates $(300 \mu \mathrm{g})$ were run on SDS-PAGE, transferred to nitrocellulose and blotted with polyclonal antisera which recognises both $\operatorname{PKB} \alpha$ and $\operatorname{PKB} \beta$ and bands were visualised using enhanced chemoluminescence. A representative experiment is shown but similar results were obtained in 3 separate experiments

the insulin induced increase in the level of $\mathrm{p} 42$ ERK-2 phosphorylation and at $20 \mu \mathrm{mol} / 1$ PD98059 actually reduced the level of p42 ERK-2 phosphorylation to below that seen in unstimulated muscle (Fig. 2). This indicated that PD98059 was blocking the insulin stimulated activation of the Map-kinase cascade in human skeletal muscle.

Insulin stimulation of glycogen synthase. In the current study insulin stimulated the glycogen synthase activity ratio approximately 1.7 -fold. This stimulation was not blocked by PD98059 at concentrations of either 10 or $20 \mu \mathrm{mol} / \mathrm{l}$ (Fig. 3). However $20 \mu \mathrm{mol} / 1$ PD98059 completely blocks insulin's ability to stimulate p42 ERK-2 phosphorylation in the current study and previous studies have also reported that concentrations of PD 98059 as low as $3 \mu \mathrm{mol} / \mathrm{l}$ block insulin stimulation of ERK activity [22].

Insulin stimulation of glucose transport. In the current study insulin stimulated 3-o-methylglucose uptake more than 2-fold which is in good agreement with previous studies in isolated human muscle strips [5]. At concentrations shown to block insulin stimulated phosphorylation of p42 ERK-2, PD98059 did not significantly reduce the level of insulin stimulation of 3o-methylglucose transport (Fig. 4). However, wortmannin reduced insulin stimulation of 3-o-methylglucose transport in a dose-dependent manner with an $\mathrm{IC}_{50} \approx 100 \mathrm{nmol} / \mathrm{l}$ (Fig. 5).

Insulin stimulation of protein kinase-B phosphorylation. Insulin caused a decrease in the mobility of PKB in an SDS-PAGE system (Fig. 6). Previous studies have shown that this is due to phosphorylation of $\mathrm{PKB}$ on serine and threonine and that this is associated with activation of the enzyme [15]. Both wortman$\operatorname{nin}(250 \mathrm{nmol} / \mathrm{l})$ and LY294002 (8 $\mu \mathrm{mol} / \mathrm{l})$ completely blocked the insulin induced mobility shift (Fig.6) 
indicating that PI 3-kinase is essential for activation of this enzyme in human skeletal muscle. However, the MEK inhibitor PD $98059(20 \mu \mathrm{mol} / \mathrm{l})$ did not block this insulin stimulated phosphorylation of PKB (data not shown).

\section{Discussion}

The current study provides the first investigation of the involvement of PI 3-kinase in insulin signalling to PKB and the MAP-kinase cascade in human skeletal muscle. The results of the current studies demonstrate that insulin is able to stimulate phosphorylation of MAP-kinase in human skeletal muscle. Increased phosphorylation of MAP-kinase is tightly associated with an increase in enzyme activity [23] and we find a similar relationship in human skeletal muscle. Using two independent antibodies we have not able to detect significant levels of p44 ERK-2 in human skeletal muscle strips. However, the p42 ERK-2 was readily detectable and was consistently partially phosphorylated in unstimulated human muscle strips. A similar partial phosphorylation of MAP-kinase isoforms has also previously been observed in in vitro incubations of rodent muscle $[24,25]$. The reason for this basal phosphorylation in muscle is not entirely clear, although the muscle strips are used immediately after preparation and are thus not quiescent. Therefore, it is possible that the stimulatory effects of the in vivo milieu of growth factors present in the bloodstream prior to excision may contribute to this effect. Exercise also stimulates MAP-kinase activity in rodent muscle [24] raising the possibility that contraction has also contributed to the basal level of p42 ERK-2 phosphorylation in the human muscle.

The finding that the MEK inhibitor PD 98059 is able to block insulin stimulation of p42 ERK-2 phosphorylation indicates that insulin stimulation of the MAP-kinase cascade is being blocked by this inhibitor. These results are entirely consistent with results obtained in cell culture models $[22,26]$. However, high concentrations of two separate PI 3-kinase inhibitors, wortmannin and LY294002, were unable to block the insulin induced phosphorylation of p42ERK-2 indicating that PI 3-kinase activity is not required for this process in our system. This is somewhat in contrast to the situation in cultured L6 myoblasts [27] and in primary cultures of human myoblasts [16] where $100 \mathrm{nmol} / \mathrm{l}$ wortmannin largely blocks insulin-like growth factor (IGF)-1 and insulin stimulation on p42-ERK-2. The reason for this difference is not clear, but it suggests that the ability of PI 3-kinase to regulate MAP-kinase activity becomes decoupled during differentiation from myoblasts to myotube.

In the current study wortmannin completely blocked the ability of insulin to stimulate glucose uptake in a dose dependent manner. The $\mathrm{ED}_{50}$ for this effect is around $100 \mathrm{nmol} / \mathrm{l}$ which is an order of magnitude higher than insulin's inhibitory effects on glucose transport in isolated adipocytes and cell culture models $[9,10]$. Similar observations have been made in rodent muscle where $100 \mathrm{nmol} / \mathrm{l}$ wortmannin is insufficient to completely block insulin stimulation of glucose uptake into rat muscle [28, 29]. The reason for this is not clear but wortmannin is known to be labile and the differences in efficacy could be due to increased degradation of wortmannin in muscle. Alternatively these differences could be due to differences in uptake kinetics of wortmannin in muscle as muscle strips are used in the assays and these are composed of multiple layers of cells. In contrast, in isolated adipocytes and cell culture systems, the inhibitor has direct access to the cells. However, even at $100 \mathrm{nmol} / \mathrm{l}$ wortmannin is thought to be a highly specific PI 3kinase inhibitor [for review see 30, 31]. Therefore, the findings of the current study are entirely consistant with PI 3-kinase being an essential element of signalling cascades leading from the insulin receptor to glucose transporter translocation in human skeletal muscle.

Concentrations of PD 98059 which block insulin stimulated p42 ERK-2 activation had no effect on insulin induced activation of glycogen synthase or on insulin's ability to stimulate glucose transport into human skeletal muscle. These results indicate that activation of MAP-kinase was not necessary for insulin stimulation of glucose transport in human skeletal muscle. While previous studies have suggested that the MAP-kinase cascade is an intermediary in the transduction of signals from the insulin receptor to glycogen synthase in muscle [17], the current findings suggest this is not the case in human skeletal muscle. In this respect the fully differentiated human skeletal muscle system behaves similarly to L6 myotubes [22], undifferentiated human myoblasts [16] and intact rat diaphragm muscle [32] where PD 98059 blocks insulin stimulation of MAP-kinase but not of glycogen synthase. Therefore the physiological role of insulin's stimulation of the MAP kinase cascade in muscle remains elusive.

The current study also provides the first evidence that PKB is phosphorylated in response to insulin in human skeletal muscle and that this occurs in a PI 3kinase dependent manner. This is of relevance as phosphorylation of $\mathrm{PKB}$ is closely associated with activation of the enzyme. PI 3-kinase inhibitors are also known to block insulin activation of glycogen synthase $[13,14]$ and this may involve PKB as the PKB lies between PI 3-kinase and glycogen synthase kinase 3 [15]. Lack of suitable reagents has precluded our ability to study insulin's regulation of glycogen synthase kinase 3 activity in the limited amounts of tissue available in the current studies. Further studies are required to elucidate the role of $\mathrm{PKB}$ and other 
PI 3-kinase dependent signalling molecules in the insulin stimulated signalling pathways regulating glucose metabolism in skeletal muscle.

A cknowledgements. This study was supported by grants from the British Diabetic Association, the Swedish Medical Research Council (9517, 11135 and 11823), Smith Kline Beecham Pharmaceuticals, the Nordisk Insulin Foundation, the Swedish Diabetic Association, the Gustav V's Research Foundation. Travel grants were provided by the Asher Korner Fellowship and the British Council. P.R. S. is the recipient of a British Diabetic Association R. D. Lawrence Research Fellowship.

\section{References}

1. Cheatham B, Kahn CR (1995) Insulin action and the insulin signaling network. Endocr Rev 16: 117-142

2. DeFronzo RA (1988) The triumverate: beta cell, muscle, liver. Diabetes 37: 667-687

3. DeFronzo RA, Jacot E, Jacquier E, Maeder E, Wahren J, Felber JP (1981) The effect of insulin on the disposal of intravenous glucose. Diabetes 30: 1000-1007

4. Friedman JE, Dohm GL, Leggett-Frazier N, et al. (1992) Restoration of insulin responsiveness in skeletal muscle of morbidly obese patients after weight loss. Effect on muscle glucose transport and glucose transporter GLUT4. J Clin Invest 89: 701-705

5. Zierath JR, Galuska D, Nolte LA, Thorne A, Smedgaard-Kristensen J, Wallberg-Henriksson H (1994) Effects of glycaemia on glucose transport in isolated skeletal muscle from patients with NIDDM: in vitro reversal of muscular insulin resistance. Diabetologia 37: 270-277

6. Haring HU, Mehnert H (1993) Pathogenesis of type 2 (non-insulin-dependent) diabetes mellitus: candidates for a signal transmitter defect causing insulin resistance of the skeletal muscle. Diabetologia 36: 176-182

7. Zierath JR, He L, Guma A, Wahlstrom EO, Klip A, WallbergHenriksson $H$ (1996) Insulin action on glucose transport and plasma membrane GLUT4 content in skeletal muscle of patients with NIDDM. Diabetologia 39: 1180-1189

8. Clarke JF, Young PW, Yonezawa K, Kasuga M, Holman GD (1994) Inhibition of the translocation of GLUT1 and GLUT4 in 3T3-L1 cells by the phosphatidylinositol 3-kinase inhibitor wortmannin. Biochem J 300: 631-635

9. Cheatham B, Vlahos CJ, Cheatham L, Wang L, Blenis J, Kahn CR (1994) Phosphatidylinositol 3-kinase activation is required for insulin stimulation of pp70 S6 kinase, DNA synthesis and glucose transporter translocation. Mol Cell Biol 14: 4902-4911

10. Okada T, Kawano Y, Sakakibara T, Hazeki O, Ui M (1994) Essential role of phosphatidylinositol 3-kinase in insulin induced glucose transport and antilipolysis in rat adipocytes. J Biol Chem 269: 3568-3573

11. Frevert EU, Kahn BB (1997) Differential effects of constitutively active phosphatidylinositol 3-kinase on glucose transport, glycogen synthase activity and DNA synthesis in 3T3-L1 adipocytes. Mol Cell Biol 17: 190-198

12. Tanti J, Gremeaux T, Grillo S, et al. (1996) Overexpression of a constitutively active form of phosphatidylinositol 3-kinase is sufficient to promote GLUT4 translocation in adipocytes. J Biol Chem 271: 25227-25232

13. Yamamoto-Honda R, Tobe K, Kaburagi Y, et al. (1995) Upstream mechanisms of glycogen synthase activation by insulin and insulin like growth factor. J Biol Chem 270: 2729-2734

14. Shepherd PR, Nave BT, Siddle K (1995) Insulin stimulation of glycogen synthesis and glycogen synthase activity is blocked by wortmannin and rapamycin in 3T3-L1 adipocytes: evidence for the involvement of phosphoinositide 3-kinase and p-70 ribosomal protein-S6 kinase. Biochem J 305: 25-28

15. Cross DAE, Alessi DR, Cohen P, Andjelkovich M, Hemmings BA (1995) Inhibition of glycogen synthase kinase 3 by insulin mediated by protein kinase B. Nature 378: 785-789

16. Hurel SJ, Rochford JJ, Borthwick AC, et al. (1996) Insulin action in cultured human myoblasts: contribution of different signalling pathways to regulation of glycogen synthesis. Biochem J 320: 871-877

17. Dent P, Lavoinne A, Nakienly S, Caudwell FB, Watt P, Cohen $P$ (1990) The molecular mechanism by which insulin stimulates glycogen synthesis in mammalian skeletal muscle. Nature 348: 302-308

18. Denton RM, Tavare JM (1995) Does MAP kinase have a role in insulin action: the case for and against. Eur J Biochem 227: 597-611

19. Zierath JR (1995) In vitro studies of human skeletal muscle: hormonal and metabolic regulation of glucose transport. Acta Physiol Scand 155 [Suppl] 626: 1-95

20. Wallberg-Henriksson H, Zetan N, Henriksson J (1987) Reversibility of decreased insulin stimulated glucose transport capacity in diabetic muscle with in vitro incubation: insulin is not required. J Biol Chem 262: 7665-7671

21. Thomas JA, Schlender KK, Larner J (1968) A rapid filter assay for UDP glucose glycogen-glucosyl transferase. Anal Biochem 25: 486-499

22. Lazar D, Wiese RJ, Brady MJ, et al. (1995) Mitogen activated protein kinase kinase inhibition does not block the stimulation of glucose utilization by insulin. J Biol Chem 270: 20801-20807

23. L'Allemain G, Her J, Wu J, Sturgill TW, Weber MJ (1992) Growth factor induced activation of a kinase activity which causes regulatory phosphorylation of p42 Map kinase. Mol Cell Biol 12: 2222-2229

24. Goodyear LJ, Chang P, Sherwood DJ, Dufresne SD, Moller DE (1996) Effects of excercise and insulin on mitogen activated protein kinase signalling pathways in rat skeletal muscle. Am J Physiol 271: E403-E408

25. Chang P, LeMarchand-Brustel Y, Cheatham LA, Moller DE (1995) Insulin stimulation of mitogen activated protein kinase, p90Rsk, and p70s6kinase in skeletal muscle of normal and insulin resistant mice. J Biol Chem 270: 29928-29935

26. Dudley DT, Pang L, Decker SJ, Bridges AJ, Saltiel AR (1995) A synthetic inhibitor of the mitogen activated protein kinase cascade. Proc Natl Acad Sci USA 92: 7686-7689

27. Cross DAE, Alessi DR, Vandenheede JR, McDowell HE, Hundal HS, Cohen P (1994) The inhibition of glycogen synthase kinase- 3 by insulin or insulin like growth factor 1 in the rat skeletal muscle cell L6 is blocked by wortmannin, but not rapamycin: evidence that wortmannin blocks activation of the mitogen activated protein kinase pathway in L6 cells between Ras and Raf. Biochem J 303: 21-26

28. Yeh J, Gulve EA, Rameh L, Birnbaum MJ (1995) The effects of wortmannin on rat skeletal muscle. J Biol Chem 270: 21072111

29. Lund S, Holman GD, Schmitz O, Pedersen O (1995) Contraction stimulates translocation of glucose transporter Glut4 in skeletal muscle through a mechanism distinct from that of insulin. Proc Natl Acad Sci USA 92: 5817-5821

30. Shepherd PR, Nave BT, O'Rahilly S (1996) Role of PI 3-kinase in insulin signalling. J Molec Endocrinol 17: 175-184

31. Ui M, Okada T, Hazeki K, Hazeki O (1995) Wortmannin as a unique probe for an intracellular signalling protein, phosphoinositide 3-kinase. TIBS 20: 303-307

32. Azpiazu I, Saltiel AR, DePaoli-Roach AA, Lawrence JC (1996) Regulation of both glycogen synthase and PHAS-1 by insulin in rat skeletal muscle involves mitogen activated protein kinase independent and rapamycin sensitive pathways. J Biol Chem 271: 5033-5039 